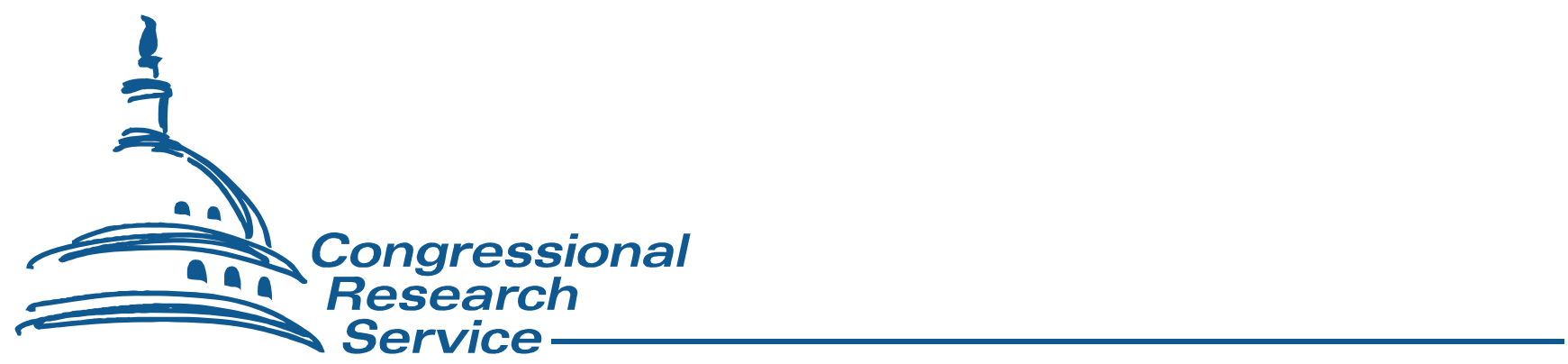

\title{
Regulation of Dietary Supplements
}

\author{
Amalia K. Corby-Edwards \\ Analyst in Public Health and Epidemiology \\ May 6, 2013
}




\section{Summary}

Many Americans take dietary supplements with the intention of meeting their nutritional needs, as well as to improve or maintain their overall health. These consumers want accurate information on the effectiveness and proper use of dietary supplements and access to the dietary supplements of their choice. The federal government has an interest in ensuring that the supplements Americans consume are high quality, free from contaminants, and accurately labeled. Because dietary supplements are intended to supplement the diet, their processing and manufacture are regulated by the U.S. Food and Drug Administration (FDA) in a manner similar to food, with some differences that will be outlined in this report. The Federal Trade Commission (FTC), in coordination with the FDA, regulates dietary supplement advertising.

In contrast with the authority under which drugs and medical devices are regulated, dietary supplements are regulated as food under the Federal Food, Drug, and Cosmetic Act (FFDCA), and the FDA does not take regulatory action on food or dietary supplements until something goes wrong with a product that is on the market. The FDA has the authority to take action regarding supplements that are labeled incorrectly (misbranded) or contain unsafe ingredients (adulterated). The FDA is made aware of potential misbranding or adulteration through inspections, adverse event reports, and citizen petitions.

The Dietary Supplement Health and Education Act of 1994 (DSHEA, P.L. 103-417) authorized the FDA to promulgate regulations for dietary supplement-specific good manufacturing practices (GMP), and established requirements for new dietary ingredients (NDI), labeling, and certain health claims for dietary supplements. Under the Dietary Supplement and Non-Prescription Drug Consumer Protection Act (P.L. 109-462), Congress added requirements for mandatory reporting of adverse events, and the Public Health Security and Bioterrorism Preparedness and Response Act (P.L. 107-188) required registration of food (including dietary supplement) manufacturers, processors, and packers with the FDA. The Food Safety Modernization Act (FSMA, P.L. 111353) provided the FDA with mandatory recall authority for adulterated food (including dietary supplements) and food containing undisclosed allergens.

Consumers, the health care and dietary supplement industries, Congress, and federal regulators all have a stake in supplement identification, effectiveness, and safety. Current federal policy toward regulating dietary supplements was intended to balance these competing interests. DSHEA provided FDA the authority to take action against products that were unsafe or adulterated, but emphasized that FDA should not take actions that would impose unreasonable regulatory barriers limiting or slowing the flow of safe products and accurate information to consumers. As the supplement market has grown and diversified, the regulatory and research questions have become more complex. This report discusses current areas of regulatory and legislative concern, including the identification of products as dietary supplements, their role in individuals' health and health care, and recent issues regarding supplement safety. 


\section{Contents}

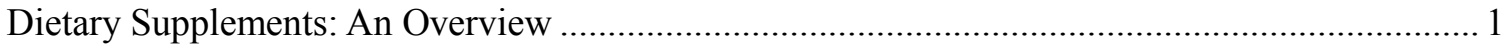

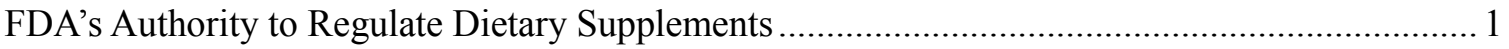

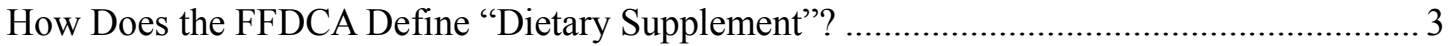

FDA Dietary Supplement-Specific Regulations and Guidance............................................. 3

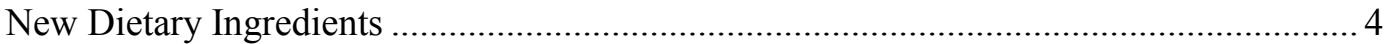

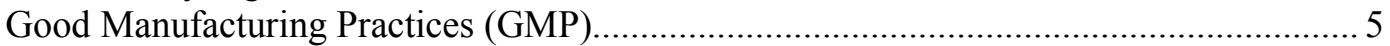

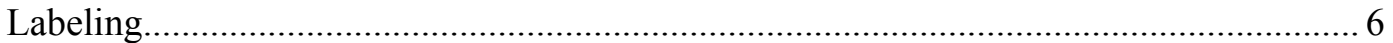

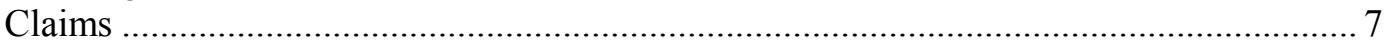

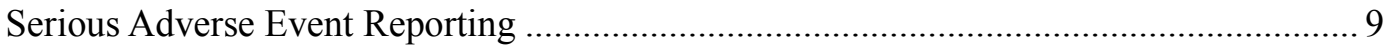

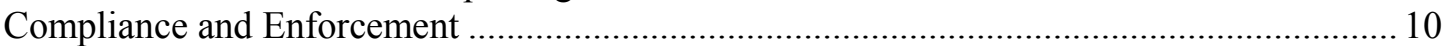

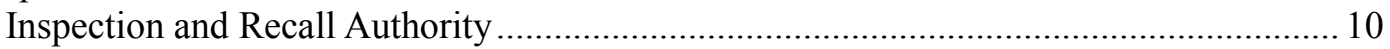

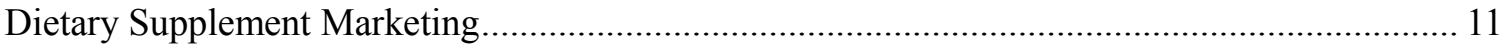

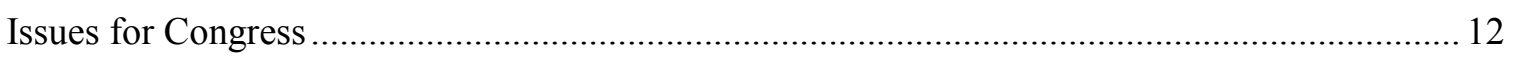

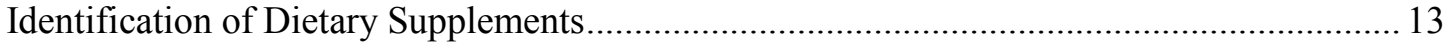

Food and Dietary Supplements: The Case of Energy Drinks......................................... 13

Drugs and Dietary Supplements: The Case of Pyridoxal 5-Phosphate .............................. 15

The Role of Dietary Supplements in Health and Health Care .............................................. 16

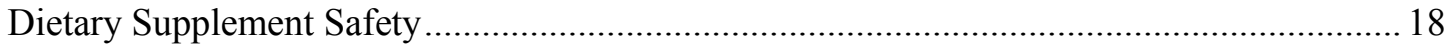

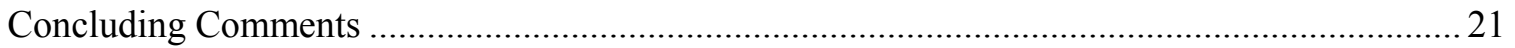

\section{Figures}

Figure B-1. Example of a Dietary Supplement Principal Display Panel

\section{Appendixes}

Appendix A. Selected Laws Regulating Dietary Supplements............................................. 22

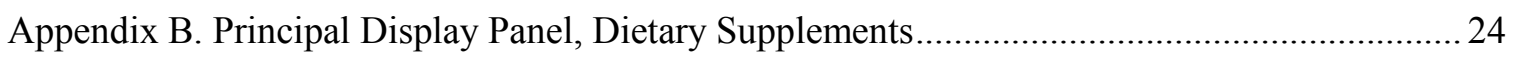

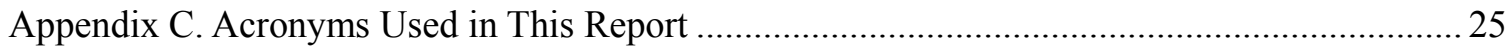

\section{Contacts}

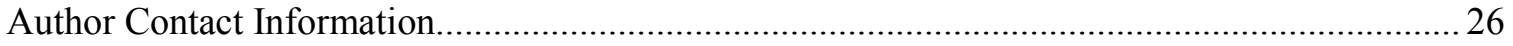

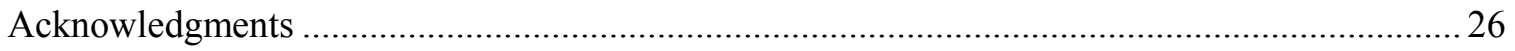




\section{Dietary Supplements: An Overview}

Dietary supplements are marketed for nutritional support and health promotion, as well as for a number of other uses, including weight loss and sports performance enhancement. These products come in pill, capsule, and liquid form, as well as in forms that may appear similar to conventional food or beverages. Dietary supplement use is common in the U.S. population; over one-half of U.S. adults over age 20 take dietary supplements. ${ }^{1}$ Surveys show that number has been increasing. ${ }^{2}$

Dietary supplement production has increased over time. The number of dietary supplements on the market rose from 4,000 in 1994 to approximately 55,000 in 2009. ${ }^{3}$ The industry recorded over $\$ 30$ billion in sales in 2011. ${ }^{4}$ In 2010-2011, top-selling supplements included vitamins, herbs and botanicals, sports nutrition supplements, and "specialty" supplements which the industry defines as supplements such as glucosamine, probiotics, dehydroepiandrosterone (DHEA), and fish oil that do not fit into other supplement categories. ${ }^{5}$

This report outlines FDA's authority to regulate dietary supplements and summarizes dietary supplement-specific regulations for new dietary ingredients (NDI), good manufacturing practices (GMP), labeling, and claims. The report also discusses adverse event reporting for dietary supplements and other means of ensuring consumer safety through enforcement of these authorities and regulations. Dietary supplement advertising, which is regulated by the Federal Trade Commission (FTC) in coordination with the FDA, is also discussed. Finally, the report concludes with a discussion of policy issues related to the manufacture, regulation, and use of dietary supplements, including the identification of dietary supplements, the role of dietary supplements in health and health care, and dietary supplement safety.

\section{FDA's Authority to Regulate Dietary Supplements}

The Food and Drug Administration (FDA) in the U.S. Department of Health and Human Services (HHS) regulates the processing, manufacture, and packaging of dietary supplements under the Federal Food, Drug, and Cosmetic Act (FFDCA) of $1938 .{ }^{6}$ Since passage of the FFDCA, the federal government has generally regulated dietary supplements as food. ${ }^{7}$ FDA's authority

\footnotetext{
${ }^{1}$ Centers for Disease Control and Prevention, Dietary Supplement Use Among U.S. Adults Has Increased Since NHANES III (1988-1994), NCHS Data Brief, April 2011, http://www.ncbi.nlm.nih.gov/pubmed/21592424.

${ }^{2}$ Ibid.

${ }^{3}$ Data from the Nutrition Business Journal cited in U.S. Government Accountability Office, Dietary Supplements: FDA May Have Opportunities to Expand its Use of Reported Health Problems to Oversee Products, GAO-13-244, March 2013, p. 1, http://www.gao.gov/products/GAO-13-244.

4 “NBJ's Supplement Business Report 2012,” Nutrition Business Journal, pp. http://newhope360.com/site-files/ newhope360.com/files/uploads/2012/10/TOC_SUMM120928.supp\%20report\%20FINAL\%20standard.pdf.

${ }^{5}$ Nutrition Business Journal consumer sales estimates: http://newhope360.com/.

${ }^{6} 21$ U.S.C. $\$ 341$ et seq.

${ }^{7}$ FDA regulates food labeling, bottled water, food additives, infant formulas, and the safety of food products (except for most meat and poultry products, which are regulated by the U.S. Department of Agriculture). See http://www.fda.gov/AboutFDA/Transparency/Basics/ucm194879.htm. See also CRS Report RS22600, The Federal Food Safety System: A Primer, by Renée Johnson.
} 
specifically in regard to dietary supplements has been amended by subsequent legislation; these authorities and their implementation and enforcement are discussed in this section. ${ }^{8}$

Under the FFDCA, the FDA regulates the processing, manufacture, and labeling of food products. The agency has the authority to deem food (and dietary supplements) misbranded (i.e., inaccurately labeled or presenting unapproved claims) ${ }^{9}$ and adulterated (i.e., containing ingredients that pose a significant or unreasonable risk of illness or injury). ${ }^{10}$ The law authorizes the FDA to recall food (and dietary supplements) under specified circumstances.

Nutrition labeling requirements for food, including dietary supplements, were established under the Nutrition Labeling Education Act of 1990 (NLEA). ${ }^{11}$ However, the Dietary Supplement Act of $1992^{12}$ instituted a one year moratorium on the implementation of dietary supplement labeling under NLEA. Congress subsequently required the FDA to create dietary supplement-specific regulations for labeling under the Dietary Supplement Health and Education Act of 1994 (DSHEA). ${ }^{13}$

DSHEA made changes to FDA's authority that differentiated certain aspects of dietary supplement regulation from regulation of conventional foods, in regard to 1) new dietary ingredients ${ }^{14}$ (NDI), 2) good manufacturing practices (GMP), 3) labeling, and 4) certain health claims for dietary supplements. Additionally, DSHEA excluded dietary supplement ingredients from the definition of a food additive. ${ }^{15}$ The Public Health Security and Bioterrorism Preparedness and Response Act ${ }^{16}$ required registration of food (including dietary supplement) manufacturers, processors, and packers with the FDA. Subsequent legislation provided FDA with additional authorities. Under the Dietary Supplement and Non-Prescription Drug Consumer Protection Act, Congress added requirements for mandatory reporting of adverse events for dietary supplements. ${ }^{17}$ Most recently, the Food Safety Modernization Act $^{18}$ (FSMA) provided the FDA with mandatory recall authority for adulterated food (including dietary supplements) and for food that does not provide adequate allergen labeling.

Within the FDA, regulation of both food and dietary supplements falls within the purview of the Office of Foods, Center for Food Safety and Applied Nutrition (CFSAN). ${ }^{19}$ Information on CFSAN oversight of dietary supplements is summarized in the text box below.

\footnotetext{
${ }^{8}$ Appendix A of this report provides a list of selected laws that impact dietary supplement regulation.

${ }^{9} 21$ U.S.C. $\$ 343$.

${ }^{10} 21$ U.S.C. $\$ 342$.

${ }^{11}$ P.L. 101-535.

${ }^{12}$ P.L. 102-571, Section 202.

${ }^{13}$ P.L. 103-417, Section 7.

${ }^{14}$ See "New Dietary Ingredients" in this report.

${ }^{15} 21$ U.S.C. $\$ 348$. FDA defines a food additive as "any substance the intended use of which results or may reasonably be expected to result — directly or indirectly — in its becoming a component or otherwise affecting the characteristics of any food." 21 C.F.R. $\S 170.3$.

${ }^{16}$ P.L. 107-188, Section 305.

${ }^{17}$ P.L. 109-462, Section 3.

${ }^{18}$ P.L. 111-353, Section 206

${ }^{19}$ Food and Drug Administration, Regulatory Procedures Manual, Silver Spring, MD, 2011, http://www.fda.gov/ ICECI/compliancemanuals/regulatoryproceduresmanual/default.htm\#_top.
} 


\section{Dietary Supplement Oversight in FDA's Center for Food Safety and Applied Nutrition}

The Office of Nutrition, Labeling, and Dietary Supplements (ONDLS) has oversight of food and nutrition labeling, including that of dietary supplements. The Food Labeling and Standards staff of ONDLS reviews food product labeling for adherence to regulations; the Nutrition Programs staff conducts scientific and regulatory review of health claims petitions, nutrient content claim petitions, and analyses of nutrition labeling; and the Division of Dietary Supplement Programs has primary responsibility for other product labeling issues, such as monitoring structure/function claim notifications, safety assessments for the New Dietary Ingredient (NDI) notification program, general dietary supplement policy, and responding to petitions and industry-related notifications.

The Office of Regulatory Science, in conjunction with the Office of Applied Research and Safety Assessment, manages and conducts the safety assessments, compliance, and regulatory programs relevant to dietary supplement labeling requirements and claims of unsafe, adulterated, or contaminated dietary supplement products. ${ }^{20}$

\section{How Does the FFDCA Define "Dietary Supplement"?}

Prior to DSHEA, there was no statutory definition of dietary supplements. As amended by DSHEA, the FFDCA defines a dietary supplement as a product (other than tobacco) that is not represented as a conventional food and

- $\quad$ is intended to supplement the diet;

- contains one or more of the following dietary ingredients: vitamins, minerals, herbs or other botanicals, amino acids, and other substances or their constituents;

- is intended to be taken by mouth as a pill, capsule, powder, tablet, or liquid; and

- $\quad$ is labeled on the front panel as being a dietary supplement. ${ }^{21}$

\section{FDA Dietary Supplement-Specific Regulations and Guidance}

As noted, dietary supplements are generally regulated as food under the FFDCA. ${ }^{22}$ As such, they are subject to fewer premarket regulations than other items within the FDA's regulatory purview, such as drugs and medical devices. ${ }^{23}$ Similar to food manufacturers, dietary supplement manufacturers must register with the FDA, follow current good manufacturing practices (GMP), and must abide by nutrition labeling and claims regulations. ${ }^{24}$ However, by law, some of these regulations are dietary supplement-specific. Unlike food manufacturers, dietary supplement manufacturers are required to report serious adverse events to the FDA.

In contrast to drugs, dietary supplements and their ingredients are generally presumed safe; also unlike with drugs, the FDA does not have the authority to require safety and efficacy testing for dietary supplements before they enter the market. Although processors, manufacturers, and packers of dietary supplements are expected to adhere to FDA regulations when bringing a new

${ }^{20}$ Ibid. at 1-6-5.

${ }^{21} 21$ U.S.C. $\$ 321(\mathrm{ff})$.

2221 U.S.C. $\$ 401$ et seq.

${ }^{23}$ For more information on drug and device regulation at the FDA, see CRS Report R42130, FDA Regulation of Medical Devices, by Judith A. Johnson and CRS Report R41983, How FDA Approves Drugs and Regulates Their Safety and Effectiveness, by Susan Thaul.

${ }^{24} 21$ C.F.R. $\$ 111$. 
product to market, there is no pre-market approval process for dietary supplements. However, prior to entering the market, the FDA must be notified of dietary supplements containing New Dietary Ingredients (NDI), and of dietary supplements containing certain claims. After a supplement is on the market, FDA has the authority to deem dietary supplements misbranded or adulterated if they are inaccurately labeled, contain unapproved NDI, or contain harmful ingredients, and may issue warnings or order a mandatory recall in certain circumstances. ${ }^{25}$ However, the burden is on the government to prove such claims.

The following sections provide details on FDA's dietary supplement-specific authorities, regulations, and guidance on NDI, GMP, labeling (including packaging, inserts, and information at the point of sale), claims, and serious adverse event reporting.

\section{New Dietary Ingredients}

A NDI is defined as a dietary ingredient that was not marketed in the United States in a dietary supplement before October 15, $1994 .{ }^{26}$ Supplement ingredients sold in the United States before October 15, 1994 are presumed safe based on their history of use by humans and do not need to be reviewed for safety by the FDA. For these grandfathered dietary supplement ingredients, manufacturers are required to maintain records that document their use prior to October 15, 1994. As long as documentation of grandfathered status exists, a product may be marketed without any evidence of efficacy or safety of its ingredients. The manufacturer of a NDI marketed after that date must give 75 days' premarket notification to the FDA, and must provide a history of use or other evidence of safety when used under recommended conditions. ${ }^{27}$

Prior to enactment of DSHEA in 1994, manufacturers were not required by law to notify the FDA of dietary supplement ingredients. Congress created a requirement for manufacturers to notify the FDA of NDI in DSHEA. ${ }^{28}$ There is, however, no list of dietary supplement ingredients that were on the market prior to that date. FSMA, enacted in December 2010, contained a provision requiring the FDA to clarify the definition of a NDI and to explain the requirements for safety evaluation of a NDI within 180 days of enactment. ${ }^{29}$ The FDA published draft NDI guidance on July $5,2011 .^{30}$ The draft guidance generated controversy, with some manufacturers expressing concerns that the proposed guidance was burdensome and not in keeping with DSHEA. ${ }^{31}$ In response to those concerns, the FDA agreed in June 2012 to revise the guidance. FDA has not proposed a timeline for the revised guidance. ${ }^{32}$

\footnotetext{
${ }^{25}$ P.L. 111-353, Section 206.

${ }^{26} 21$ U.S.C. $\$ 350$ b.

${ }^{27}$ Food and Drug Administration, "Draft Guidance for Industry, Dietary Supplements: New Dietary Ingredient Notifications and Related Issues," 79 Federal Register 39111, July 5, 2011.

${ }^{28}$ P.L. 103-417, Section 8.

${ }^{29}$ P.L. 111-353, Section 113.

${ }^{30}$ Food and Drug Administration, "Draft Guidance for Industry, Dietary Supplements: New Dietary Ingredient Notifications and Related Issues," 79 Federal Register 39111, July 5, 2011.

${ }^{31}$ Natural Products Association, "New Dietary Ingredients Draft Guidance," http://www.npainfo.org/NPA/Advocacy/ NDI\%20Draft\%20Guidance.aspx.

${ }^{32}$ Natural Products Insider, "FDA Reportedly to Revisit NDI Draft Guidance," press release, June 19, 2012, http://www.naturalproductsinsider.com/news/2012/06/fda-reportedly-to-revisit-ndi-draft-guidance.aspx.
} 
For each NDI, manufacturers are required to submit notifications to the FDA, and the ingredient must either (1) have been present in the food supply as an article used for food in a form in which the food has not been chemically altered, or (2) provide evidence supporting a "reasonable expectation of safety" under the recommended conditions of use. According to FDA's draft guidance, for ingredients that are not grandfathered (or if a manufacturer is unable to produce the relevant documentation to confer grandfathered status) the manufacturer would have to recharacterize the ingredient as a NDI and follow the relevant regulatory process. ${ }^{33}$

\section{Good Manufacturing Practices (GMP)}

Dietary supplement processors, manufacturers, and packers are responsible for ensuring that a dietary supplement or dietary supplement ingredient is safe by following GMP. ${ }^{34}$ GMP establish the minimum standards for activities related to manufacturing, packaging, labeling, or holding dietary supplements for the purposes of ensuring the product's quality throughout the manufacturing process to minimize the risks of a potentially unsafe or otherwise illegal product from reaching the marketplace.

DSHEA gave FDA the authority to establish GMP specific to dietary supplements modeled after the existing GMP for food. ${ }^{35}$ Dietary supplement-specific GMP were requested by industry, citing concerns that GMP developed for conventional food products did not adequately address the unique characteristics of dietary supplements. These regulations were finalized in $2007,{ }^{36}$ and largely addressed the concerns raised by the industry. Dietary supplement GMPs contain sections that detail additional quality control procedures and recordkeeping requirements for each step in the manufacturing process. ${ }^{37}$ Following GMP should ensure that final products do not include the wrong ingredients; too much or too little of a dietary ingredient; ${ }^{38}$ contaminants such as natural toxins, bacteria, pesticides, glass, lead or other heavy metals; or improper packaging or labeling. FDA noted in the final rule that "the focus of GMP is on process controls to ensure that the desired outcome is consistently achieved, and not on the inherent safety of the ingredients used." 39

GMP for dietary supplements apply to all domestic and foreign companies that manufacture, package, label, or hold a dietary supplement for import and sale in any state or territory of the United States, the District of Columbia, or Puerto Rico. ${ }^{40}$ This includes those involved with

\footnotetext{
${ }^{33}$ Food and Drug Administration, "Draft Guidance for Industry, Dietary Supplements: New Dietary Ingredient Notifications and Related Issues," 79 Federal Register 39111, July 5, 2011.

${ }^{34} 21$ U.S.C. $\$ 342(\mathrm{~g})$.

3521 U.S.C. $\$ 342(\mathrm{~g})$.

${ }^{36}$ Food and Drug Administration, "Current Good Manufacturing Practice in Manufacturing, Packaging, Labeling, or Holding Operations for Dietary Supplements; Final Rule," 72 Federal Register 34752-34958, June 25, 2007.

${ }^{37}$ Food and Drug Administration, "Dietary Supplement Current Good Manufacturing Practices (CGMPs) and Interim Final Rule (IFR) Facts,” press release, June 22, 2007, http://www.fda.gov/Food/GuidanceRegulation/CGMP/ ucm110858.htm.

${ }^{38}$ Some researchers note that, for most botanicals, consensus has not been reached on analytical markers or standardized analytical methods for determining the presence or quantity of the botanical. For example, see J Kemsley, "Botanical Scrutiny," Chemical and Engineering News, March 18, 2013, pp. 12-17.

${ }^{39}$ Food and Drug Administration, "Dietary Supplement Current Good Manufacturing Practices (CGMPs) and Interim Final Rule (IFR) Facts,” press release, June 22, 2007, http://www.fda.gov/Food/GuidanceRegulation/CGMP/ ucm110858.htm.

4021 C.F.R. $\$ 111.1$
} 
testing, quality control, packaging and labeling, and distribution of dietary supplements, but excludes retail establishments that are solely involved in the direct sale of dietary supplements to individual consumers.

\section{Labeling}

Although dietary supplements are generally considered food for purposes of FDA regulation, they have different labeling requirements set forth under the FFDCA. Dietary supplement labeling includes packaging, inserts, and information at the point of sale. The 1938 FFDCA required that foods contain labels with certain nutritional information, but it was not until the 1990s that food labeling regulations were authorized and promulgated. The Nutrition Labeling and Education Act (NLEA) of 1990 amended the FFDCA to require that all foods, with certain exceptions, bear nutritional content labels. ${ }^{41}$ The Dietary Supplement Act of 1992 created a one year moratorium on the implementation of NLEA with respect to dietary supplement labeling. ${ }^{42}$ DSHEA provided FDA the authority to promulgate labeling regulations specific to dietary supplements. ${ }^{43}$ While similar to the requirements for nutrition labeling of food, dietary supplement labeling requirements now differ in several specific aspects. ${ }^{44}$

Under the FFDCA, the FDA may deem a dietary supplement misbranded if it does not follow the relevant labeling regulations. ${ }^{45}$ Dietary supplements are required to have a supplement facts panel (as opposed to a nutrition facts panel for conventional foods). ${ }^{46}$ Dietary supplement labels may display certain claims, discussed in detail below, but they must also display a standard disclaimer, and must not link the supplement or its ingredients to the treatment of a specific medical condition. The FDA's Dietary Supplement Labeling Guide sets forth the general display (principal display panel, or PDP) and placement requirements of dietary supplement labeling. ${ }^{47}$ An example of a dietary supplement PDP is shown in Figure B-1. Dietary supplement labels are required to have the following information:

- a statement of identity (name of the dietary supplement); $;^{48}$

- the net quantity of contents statement (amount of the dietary supplement) ${ }^{49}$

- a Supplement Facts Panel; ${ }^{50}$

${ }^{41}$ P.L. 101-535, Section 2.

${ }^{42}$ P.L. 102-571, Section 202.

${ }^{43}$ P.L. 103-417, Section 7.

${ }^{44}$ For specific information on these differences, see Food and Drug Administration, Guidance for Industry: A Dietary Supplement Labeling Guide, April 2005, http://www.fda.gov/Food/GuidanceComplianceRegulatoryInformation/ GuidanceDocuments/DietarySupplements/DietarySupplementlabelingguide/default.htm.

${ }^{45} 21$ U.S.C. $\$ 343$.

${ }^{46}$ P.L. 103-417, Section 7. Regulations regarding the layout and content of the supplement facts panel are at 21 C.F.R. $\$ 101.36$.

${ }^{47}$ Food and Drug Administration, Guidance for Industry: A Dietary Supplement Labeling Guide, April 2005, http://www.fda.gov/Food/GuidanceComplianceRegulatoryInformation/GuidanceDocuments/DietarySupplements/ DietarySupplementlabelingguide/default.htm.

4821 C.F.R. \$101.3(a).

${ }^{49} 21$ C.F.R. $\$ 101.105(\mathrm{a})$.

${ }^{50} 21$ C.F.R. §101.36. 
- an ingredients list, and the quantity of such ingredients in the product; with the exception of quantities for the ingredients included in "proprietary blends," which do not need to be listed; ${ }^{51}$ and

- the name and place of business of the manufacturer, packer, or distributor. ${ }^{52}$

\section{Claims}

In addition to the required labeling, the FFDCA permits (but does not require) manufacturers to make certain types of claims about supplements' benefits. ${ }^{53}$ Dietary supplement manufacturers may not legally claim that their product will diagnose, cure, mitigate, treat, or prevent a specific disease, and certain claims require FDA-approved disclaimers. ${ }^{54}$ FDA guidance provides details on the disclaimers that must accompany certain claims on the product label. ${ }^{55}$ Similar to food manufacturers, dietary supplement manufacturers may make nutrient content claims and health claims. ${ }^{56}$ They may also make structure/function claims. ${ }^{57}$ These claims are explained below.

\section{Nutrient Content Claims}

A nutrient content claim is one that expressly or implicitly characterizes the level of a nutrient in a dietary supplement. ${ }^{58}$ An expressed nutrient content claim (for example, "contains 100 calories") is one that contains a direct statement about the level or range of a nutrient within the dietary supplement. ${ }^{59}$ An implied nutrient content claim is one that either (1) describes the nutrient in a manner that suggests that it is absent or present in a certain amount (for example, "high in oat bran") or (2) suggests that the dietary supplement, because of its nutrient content, may be useful in maintaining healthy dietary practices and is made in association with an express claim or statement about a nutrient. ${ }^{60}$

\section{Health Claims}

Health claims describe a relationship between a food, food component, or dietary supplement ingredient, and reducing risk of a disease or health-related condition ${ }^{61}$ (for example, "While many factors affect heart disease, diets low in saturated fat and cholesterol may reduce the risk of this disease.") These claims can be made through written statements, symbols, or vignettes.

\footnotetext{
${ }^{51} 21$ C.F.R. $\S 101.4(\mathrm{a})(1)$.

5221 C.F.R. $\S 101.105$.

5321 U.S.C. $\$ 343(\mathrm{r})$.

${ }^{54}$ P.L. 103-417, Section 5.

${ }^{55}$ Food and Drug Administration, Guidance for Industry: A Dietary Supplement Labeling Guide, April 2005, http://www.fda.gov/Food/GuidanceRegulation/GuidanceDocumentsRegulatoryInformation/DietarySupplements/ ucm070613.htm\#6-43.

5621 U.S.C. $\$ 343(\mathrm{r})$.

${ }^{57}$ While structure/function claims are only authorized for dietary supplements (21 USC \$343(r)(6) and 21 CFR $\S 101.93(\mathrm{f}))$, they are also widely used for food, and their use is not prohibited in statute, regulations, or guidance.

5821 C.F.R. $\$ 101.13(\mathrm{~b})$.

${ }^{59} 21$ C.F.R. $\$ 101.13(\mathrm{~b})(1)$.

${ }^{60} 21$ C.F.R. $\S 101.13(b)(1)$ and (2); and 21 C.F.R. $\S 101.65$.

${ }^{61} 21$ C.F.R. $\S 101.14$.
} 
For the FDA to authorize use of a health claim on dietary supplement labeling, it must meet certain criteria. ${ }^{62}$ Generally, they must meet a significant scientific agreement (SSA) standard as determined by the FDA, in order to be authorized in regulation by the FDA. ${ }^{63}$ The FDA authorizes health claims only when the agency "determines, based on the totality of publicly available scientific evidence (including evidence from well-designed studies conducted in a manner which is consistent with generally recognized scientific procedures and principles), that there is significant scientific agreement, among experts qualified by scientific training and experience to evaluate such claims, that the claim is supported by such evidence."64

Health claims may also be authorized based on authoritative statements from federal scientific bodies. The latter type of claim was authorized in the FDA Modernization Act (FDAMA). ${ }^{65}$ To date, the FDA has authorized sixteen health claims; twelve are explicitly authorized in regulations and four are authorized based upon authoritative statements from federal scientific bodies (for example, a statement by the National Heart, Lung, and Blood Institute). ${ }^{66}$

Another type of health claim, known as a qualified health claim, may also be used for dietary supplements. Qualified health claims are based on less scientific evidence than the SSA required for other health claims, but must be approved by the FDA (however, they are not required to be authorized in statute or an authorizing regulation) ${ }^{67}$ FDA guidance provides standardized qualifying language to use with qualified health claims. ${ }^{68}$

\section{Structure/Function Claims}

In addition to health and nutrient content claims, dietary supplement manufacturers are allowed to make statements describing the role of their nutrients' or dietary ingredients' intended effect on the structure or function of the body. ${ }^{69}$ Structure/function claims describe how a product may affect the organs or systems of the body, but cannot mention any specific disease ${ }^{70}$ (for example, "calcium builds strong bones"). A structure/function claim describes the role of a dietary

\footnotetext{
6221 C.F.R. $\$ 101.14(\mathrm{~b})(1)-(3)$.

6321 U.S.C. $\$ 343(\mathrm{r})$.

${ }^{64} 21$ U.S.C. $\$ 343(r)(3)(B)(i) ; 21$ C.F.R. 101.14(c). This standard is referred to as the significant scientific agreement (SSA) standard. For more information on the SSA review process, see U.S. Food and Drug Administration, Guidance for Industry: Evidence-Based Review System for the Scientific Evaluation of Health Claims, Silver Spring, MD, January 2009, http://www.fda.gov/Food/GuidanceComplianceRegulatoryInformation/GuidanceDocuments/ FoodLabelingNutrition/ucm073332.htm.

${ }^{65}$ P.L. 105-115, Section 303.

${ }^{66}$ Food and Drug Administration, Guidance for Industry: A Food Labeling Guide, Appendix C: Health Claims, Silver Spring, MD, October 2009, http://www.fda.gov/Food/GuidanceRegulation/ GuidanceDocumentsRegulatoryInformation/LabelingNutrition/ucm2006828.htm.

${ }^{67}$ Food and Drug Administration, Guidance for Industry: A Food Labeling Guide, October 2009, p. Appendix D, http://www.fda.gov/Food/GuidanceRegulation/GuidanceDocumentsRegulatoryInformation/LabelingNutrition/ ucm064923.htm.

${ }^{68}$ Food and Drug Administration, Guidance for Industry: Interim Procedures for Qualified Health Claims in the Labeling of Conventional Human Food and Human Dietary Supplements, July 2003, http://www.fda.gov/Food/ GuidanceRegulation/GuidanceDocumentsRegulatoryInformation/LabelingNutrition/ucm053832.htm.

${ }^{69} 21$ U.S.C. $\$ 343(\mathrm{r})(6)$

${ }^{70} 21$ C.F.R. 101.93(f).
} 
supplement in the structure and functions of the body, and must provide truthful and nonmisleading claims that describe this role. ${ }^{71}$

Although FDA preapproval is not required for structure/function claims, manufacturers must have substantiation (evidence) for these claims, notify FDA within 30 days of a product being marketed with a structure/function claim on its label, and provide a two-part disclaimer on the supplement label. ${ }^{72}$ First, the label must state that the statement or claim has not been evaluated by the FDA. It must also state that the dietary supplement product is not intended to "diagnose, treat, cure, or prevent any disease.",73

\section{Serious Adverse Event Reporting}

As noted previously, dietary supplements are not required to undergo premarket review for safety. In order to identify safety issues, the FDA mainly relies on information provided by manufacturers under the adverse event reporting system. The FDA created a voluntary adverse event reporting system for supplements in $1993 .{ }^{74}$ This system was designed to (1) detect adverse events; (2) generate and assess signals of potential public health concerns; (3) take appropriate actions based on these assessments. However, according to HHS' Office of the Inspector General $(\mathrm{OIG})$, that system provided inadequate data on adverse events, due to its voluntary nature and limited scope. ${ }^{75}$ In 2001, an OIG report concluded that the reporting system detected relatively few adverse events, lacked adequate information to assess possible health concerns, and contained limited medical, product, and consumer information. ${ }^{76}$

The Dietary Supplement and Non-Prescription Drug Consumer Protection Act, ${ }^{77}$ enacted in 2006, required several changes to the adverse event reporting system for dietary supplements. ${ }^{78}$ It amended the FFDCA to require supplement manufacturers, packers, and distributors to submit reports of serious adverse events involving their products that occur in the United States, and it also required the FDA to create and maintain a system to track adverse events related to dietary supplements. ${ }^{79}$ The public may also submit adverse event reports to this adverse event reporting system. However, public submission of adverse event reporting is voluntary.

\footnotetext{
${ }^{71}$ Food and Drug Administration, Guidance for Industry: A Dietary Supplement Labeling Guide, April 2005, http://www.fda.gov/Food/GuidanceRegulation/GuidanceDocumentsRegulatoryInformation/DietarySupplements/ ucm070613.htm\#6-43.

${ }^{72} 21$ U.S.C. $\$ 343(\mathrm{r})(6)$.

${ }^{73} 21$ U.S.C. $\$ 343(\mathrm{r})(6) ; 21$ CFR $\S 101.93(\mathrm{f})-(\mathrm{g})$.

${ }^{74}$ Office of the Inspector General, Department of Health and Human Services, Adverse Event Reporting for Dietary Supplements: An Inadequate Safety Valve, April 2001, https:/oig.hhs.gov/oei/reports/oei-01-00-00180.pdf.

${ }^{75}$ Ibid.

${ }^{76}$ Ibid.

${ }^{77}$ P.L. 109-462, Section 3.

${ }^{78}$ Pursuant to P.L. 109-462 (21 U.S.C. \$379aa-1) an adverse event is defined as "any health-related event associated with the use of a dietary supplement that is adverse;" and a serious adverse event is defined as "an adverse event that(A) results in-(i) death; (ii) a life-threatening experience; (iii) inpatient hospitalization; (iv) a persistent or significant disability or incapacity; or (b) requires, based on reasonable medical judgment, a medical or surgical intervention to prevent an outcome described under subparagraph (A)."

${ }^{79}$ P.L. 109-462, Section 3. Information on how to submit an adverse event report can be found at http://www.fda.gov/ food/dietarysupplements/alerts/ucm111110.htm.
} 
A 2013 GAO report identified 6,307 reports of adverse events from 2008 through 2011, 71\% of which came as serious adverse events from industry, as mandated by the Dietary Supplement and Non-Prescription Drug Consumer Protection Act. ${ }^{80}$ FDA has estimated that, due to significant underreporting, the annual number of adverse events linked to dietary supplements may be $50,000 .{ }^{81}$ This may be because consumers may not consistently report adverse events to the FDA, and/or they may be contacting poison control centers which generally do not send information about adverse events to the FDA.

Adverse events that are linked to a dietary supplement or a dietary supplement ingredient by an adverse event report are usually not considered sufficient to warrant action against a product. ${ }^{82}$ However, a pattern of seemingly related events linked to a dietary supplement may cause FDA to investigate the product or take further action. ${ }^{83}$

\section{Compliance and Enforcement}

Consistent with FDA regulation of conventional foods, the FDA is not authorized to require premarket approval or review of safety and efficacy of dietary supplement products, with the exception of NDI. This contrasts with drug regulation where the manufacturer must prove the safety and efficacy prior to marketing a product ${ }^{84}$ Because the bulk of FDA's regulatory authority with regards to dietary supplements exists for products that are already on the market, this is generally where FDA concentrates its enforcement activities to determine compliance with its regulations.

\section{Inspection and Recall Authority}

FDA has the authority to take enforcement action against misbranded (i.e., inaccurately labeled or presenting unapproved claims) ${ }^{85}$ and adulterated (i.e., containing ingredients that pose a significant or unreasonable risk of illness or injury ${ }^{86}$ dietary supplements in the form of warning letters, product seizures and mandatory recalls. It may also ban an ingredient through the rulemaking process.

Under the FFDCA, a dietary supplement is considered adulterated under specified circumstances related to the product's contents and manufacturing processes: $:^{87}$

\footnotetext{
${ }^{80}$ U.S. Government Accountability Office, Dietary Supplements: FDA May Have Opportunities to Expand its Use of Reported Health Problems to Oversee Products, GAO-13-244, March 2013, p. 1, http://www.gao.gov/products/GAO13-244.

${ }^{81}$ U.S. Government Accountability Office, FDA Should Take Further Actions to Improve Oversight and Consumer Understanding, 09-250, January 2009, http://www.gao.gov/products/GAO-09-250.

${ }^{82}$ U.S. Government Accountability Office, Dietary Supplements: FDA May Have Opportunities to Expand its Use of Reported Health Problems to Oversee Products, GAO-13-244, March 2013, p. 1, http://www.gao.gov/products/GAO13-244, p. 32.

${ }^{83}$ Ibid.

${ }^{84}$ For more information on drug approval and regulation, see CRS Report R41983, How FDA Approves Drugs and Regulates Their Safety and Effectiveness, by Susan Thaul.

8521 U.S.C. $\$ 343$.

${ }^{86} 21$ U.S.C. $\$ 342$.

${ }^{87} 21$ U.S.C. $\$ 342(f)$.
} 
- if the dietary supplement or dietary ingredient presents a significant or unreasonable risk of illness or injury either (1) under conditions of use recommended or suggested in the product's labeling; or (2) under normal conditions of use, if none are set forth in the product's labeling;

- if the dietary supplement contains a NDI for which there is inadequate information as to whether or not it presents a significant or unreasonable risk of illness or injury;

- if the Secretary declares the dietary supplement or a dietary ingredient therein to pose an imminent hazard to public health or safety; or

- if the dietary supplement contains a dietary ingredient that renders it adulterated because it is a poisonous or deleterious substance rendering the product injurious to one's health.

A dietary supplement is considered misbranded if it is inaccurately labeled or presents unapproved claims. Under current law, the burden of proof of misbranding or adulteration is on the agency. ${ }^{88}$

In addition to the serious adverse event reporting system, several other mechanisms exist to identify potential safety concerns. These include conducting inspections and screening imports. FDA's capacity to carry out each of these tasks is determined by agency funding priorities ${ }^{89}$ For example, during a routine inspection of a dietary supplement manufacturer, FDA may discover unapproved drug claims ${ }^{90}$ and determine that the products are misbranded. FDA may issue a warning letter at that time. ${ }^{91}$ However, a follow-up inspection may reveal the company continuing to make certain claims. FDA may then recall or file a complaint for seizure of the products. ${ }^{92}$

\section{Dietary Supplement Marketing}

Although the FDA has broad regulatory authority over dietary supplements, the agency shares some responsibility with the Federal Trade Commission (FTC) ${ }^{93}$ While the FDA regulates claims made on product labeling (including packaging, inserts, and information at the point of sale), the FTC has primary responsibility to regulate dietary supplement advertising. ${ }^{94}$ This includes print

\footnotetext{
${ }^{88} 21$ U.S.C. $\$ 343-2(c)$.

${ }^{89}$ The 2014 FDA Congressional Budget Justification can be found at http://www.fda.gov/downloads/AboutFDA/ ReportsManualsForms/Reports/BudgetReports/UCM347422.pdf. Information related to the Office of Regulatory Affairs Field Activities (including inspections) starts on page 267.

${ }^{90}$ Dietary supplement manufacturers may not legally claim that their product will diagnose, cure, mitigate, treat, or prevent a specific disease.

${ }^{91}$ FDA warning letters are posted publicly at http://www.fda.gov/ICECI/EnforcementActions/WarningLetters/ default.htm.

${ }^{92}$ FDA's recently posted recalls can be found at http://www.fda.gov/Safety/Recalls/default.htm.

${ }^{93}$ Working Agreement Between FTC and Food and Drug Administration, 4 Trade Reg. Rep. (CCH) at 9850 (as enacted, June 9, 1954), http://www.fda.gov/ohrms/dockets/DOCKETS/06p0394/06p-0394-cp00001-10-Tab-08-TradeReg-Rpts-vol1.pdf; Updated FTC-FDA Liaison Agreement-Advertising of Over-the Counter Drugs, 4 Trade Reg. Rep. $(\mathrm{CCH})$ at 9851 (as enacted, May 14, 1971), http://www.fda.gov/ohrms/dockets/DOCKETS/06p0394/06p-0394cp00001-10-Tab-08-Trade-Reg-Rpts-vol1.pdf.

${ }^{94} 15$ U.S.C. $\$ 45(\mathrm{a})(1)$.
} 
and broadcast advertisements, infomercials, catalogs, internet marketing, and similar direct marketing materials. The FDA and FTC have the responsibility to ensure that both dietary supplement labeling and advertising is truthful, not misleading, and that any claims made may be substantiated. ${ }^{95}$

The FTC's authority derives from Section 5 of the Federal Trade Commission (FTC) Act that prohibits "unfair methods of competition in or affecting commerce, and unfair or deceptive acts or practices in or affecting commerce." ${ }^{.96}$ Additionally, the FTC Act prohibits dissemination of false advertisements by any means for the purpose of inducing the purchase of food, drugs, devices, services, or cosmetics. ${ }^{97}$ The FTC Act defines false advertisements as "any advertisement, other than labeling, which is misleading in any material respect." 98

Similar to the FDA, the FTC requires that supplement manufacturers' claims are adequately substantiated. The FTC has created a guide for industry which outlines its expectations, role, and enforcement efforts regarding substantiation. ${ }^{99}$ The FTC standard is summed up as the following:

1. Advertising must be truthful and not misleading.

2. Before disseminating an advertisement, advertisers must have adequate substantiation for all objective product claims.

The FTC defines a deceptive advertisement as one that "contains a misrepresentation or an omission that is likely to mislead consumers acting reasonably under the circumstances to their detriment." 100 The FTC's standard of substantiation for express and implied claims is one of "competent and reliable scientific evidence," " which differs from FDA's requirements for health, nutrient content, and structure/function claims. The FTC generally enforces these standards through targeted law enforcement action. ${ }^{102}$ Over the past 10 years, the FTC has filed over 100 law enforcement actions challenging claims about the efficacy or safety of a wide variety of supplements. ${ }^{103}$

\section{Issues for Congress}

Consumers, the health care and dietary supplement industries, Congress, and federal regulators all have a stake in supplement identification, effectiveness, and safety. Current federal policy toward regulating dietary supplements was intended to balance these competing interests. DSHEA

\footnotetext{
95 "Business Guide for Dietary Supplement Industry Released by FTC Staff: Guide Will Assist Industry in Ensuring Truthful Ads," Federal Trade Commission, November 18, 1998, http://www.ftc.gov/opa/1998/11/dietary.shtm. 
provided FDA the authority to step in against products that were unsafe or adulterated, but "not to take any actions to impose unreasonable regulatory barriers limiting or slowing the flow of safe products and accurate information to consumers." 104

Under current law, dietary supplements are generally regulated as food-meaning that the FDA does not take regulatory action until something goes wrong (as opposed to drug regulation, where proof of safety and efficacy are required prior to putting a product on the market). Whether this is an appropriate level of regulation has been a long-standing concern. Advocates for industry are concerned that increased regulation would stifle the dietary supplement industry. ${ }^{105}$ Public health advocates have ongoing concerns about the safety of the current approach, and have encouraged a regulatory scheme that is more similar to drug regulation. ${ }^{106}$

As the dietary supplement market has grown, regulatory and research questions have become more complex. These questions continue to reflect the fundamental balance between personal choice and safety. The following sections discuss current areas of regulatory and legislative concern, including the identification of products as dietary supplements; their role in individuals' health and health care; and recent issues regarding supplement safety.

\section{Identification of Dietary Supplements}

Although food, drugs, and dietary supplements are all defined in statute, the marketing of certain products raises questions about the regulatory schemes that should be applied. Both consumer and industry groups have asked the FDA for clarity on the factors that the agency considers when deciding whether a product is properly marketed as a dietary supplement, conventional food, or as a drug. Energy drinks, discussed below, are one example of this issue. As more products with added dietary ingredients are marketed, there may be a growing need for clarification of the boundary between conventional foods and dietary supplements, as well as further clarification between dietary supplement ingredients and drugs.

\section{Food and Dietary Supplements: The Case of Energy Drinks}

The term "energy drink" is not defined in statute or regulation. The FDA interprets the term as "a class of products in liquid form that typically contains caffeine, with or without other added ingredients." ${ }^{, 107}$ Some energy drinks are marketed as beverages while others are marketed as dietary supplements. While both beverages and dietary supplements fall under FDA's authority to regulate food products, beverages (conventional foods) and dietary supplements follow certain regulations that are different, as discussed throughout this report. Specifically, labeling, GMP, and adverse event reporting differ for dietary supplements. Additionally, conventional foods with

\footnotetext{
${ }^{104}$ P.L. 103-417, Section 2.

${ }^{105}$ Senator Orrin Hatch, "Hatch Leads Efforts to Prevent Overregulation of Dietary Supplements," press release, May 24, 2012, http://www.hatch.senate.gov/public/index.cfm/releases?ID=0b6d2f98-e486-46f7-af51-a283406efcc9.

${ }^{106}$ Senator Dick Durbin, "Durbin: FDA Should be Better Equipped to Respond to Dietary Supplement Safety Concerns," press release, May 23, 2012, http://www.durbin.senate.gov/public/index.cfm/pressreleases?ID=22a9fee5cce5-4307-970f-470272efb77b.

${ }^{107}$ Letter from Jeanne Ireland, Assistant Commissioner for Legislation, Food and Drug Administration, to The Honorable Richard J. Durbin, Senator, August 10, 2012, http://durbin.senate.gov/public/index.cfm/files/serve?File id= 17eadaa1-85e7-4ceb-a827-be244fbddfa5.
} 
added ingredients are required to follow FDA regulations on food additives ${ }^{108}$ and substances that are generally recognized as safe (GRAS) ${ }^{109}$ while dietary supplements are not (although some ingredients are regulated as NDI).

Generally, energy drink manufacturers can choose to market a product as either a conventional food or dietary supplement, depending on its intended use. However, if it appears to be a conventional food marketed as a dietary supplement, the FDA can challenge this decision. Because the decision is made by the manufacturer, there are concerns that some energy drinks are being marketed as dietary supplements in order to circumvent the required standards for food additives and GRAS substances (such as caffeine) in conventional foods. ${ }^{110}$ Conversely, there may also be benefits to marketing an energy drink as a conventional food. For example, a popular energy drink manufacturer recently changed labeling on its product to market it as a beverage. ${ }^{111}$ When marketing it as a beverage, the manufacturer is not required to report serious adverse events associated with its product. Additionally, as a beverage the energy drink is able to be purchased with food stamps. ${ }^{12}$

In a 2010 report, GAO recommended the FDA issue guidance to clarify when products should be marketed as dietary supplements or as conventional foods. ${ }^{113}$ FDA agreed with this recommendation; to date, it has issued draft guidance on distinguishing liquid dietary supplements from beverages. ${ }^{114}$ Industry representatives have raised several concerns about the draft guidance and have requested clarification from the FDA. ${ }^{115}$

Adverse event reports recently released by the FDA have potentially associated energy drinks with a number of illnesses, including heart attacks and convulsions, as well as with several deaths. ${ }^{116}$ These reports do not investigate causality or prove any direct link between energy drinks and these illnesses, and manufacturers deny any link between their products and these events. Additionally, the reports may not include adverse event reports to energy drink manufacturers who market their energy drinks as beverages, because adverse event reporting is

\footnotetext{
10821 U.S.C. $\$ 348$. FDA defines a food additive as "any substance the intended use of which results or may reasonably be expected to result — directly or indirectly — in its becoming a component or otherwise affecting the characteristics of any food." 21 C.F.R. 170.3.

${ }^{109}$ Some food additives are generally recognized as safe based under the conditions of intended use (see 21 C.F.R. $\S 170.3)$. Eligibility for classification as GRAS is determined in accordance with 21 C.F.R. $\$ 170.30$.

${ }^{110}$ B Meier, "Officials Seek Energy Drink Information," The New York Times, January 17, 2013, online edition.

${ }^{111}$ B Meier, "In a New Aisle, Energy Drinks Sidestep Some Rules,” The New York Times, March 19, 2013, online edition.

${ }^{112}$ U.S. Department of Agriculture, Supplemental Nutrition Assistance Program, "Eligible Food Items," press release, http://www.fns.usda.gov/snap/retailers/eligible.htm.

${ }^{113}$ U.S. Government Accountability Office, FDA Should Take Further Actions to Improve Oversight and Consumer Understanding, 09-250, January 2009, http://www.gao.gov/products/GAO-09-250.

${ }^{114}$ Food and Drug Administration, Guidance for Industry: Factors that Distinguish Liquid Dietary Supplements from Beverages, Considerations Regarding Novel Ingredients, and Labeling for Beverages and Other Conventional Foods, Draft Guidance, December 2009, http://www.fda.gov/food/GuidanceComplianceRegulatoryInformation/ GuidanceDocuments/ucm192702.htm.

${ }^{115}$ Natural Products Insider, "Differentiating Liquid Supplements and Beverages," press release, December 16, 2009, http://www.naturalproductsinsider.com/articles/2009/12/differentiating-liquid-supplements-and-beverages.aspx.

${ }^{116}$ Food and Drug Administration, Center for Food Safety and Applied Nutrition, Voluntary and Mandatory Reports on 5-Hour Energy, Monster Energy, and Rockstar Energy Drink, CFSAN Adverse Event Reporting System, November 2012, http://www.fda.gov/downloads/AboutFDA/CentersOffices/OfficeofFoods/CFSAN/

CFSANFOIAElectronicReadingRoom/UCM328270.pdf.
} 
not mandatory for other food manufacturers. If the FDA were to classify all energy drinks as dietary supplements, reporting of serious adverse events would be mandatory for all energy drink manufacturers. These reports have placed the issues of energy drink classification and their ingredients, and the government's role in regulating their manufacture and marketing, into the spotlight. ${ }^{117}$

Some Members of Congress have expressed concern over energy drink regulation, specifically concerning caffeine, calling on the FDA to "fix regulatory loopholes." ${ }^{118}$ Senators Durbin and Blumenthal sent several letters to the FDA in 2012 requesting regulatory action to address the "rising health concerns around energy drinks." " Until recently, FDA responded to these requests by noting that there is insufficient evidence to take action on energy drinks with added caffeine. However, in November 2012, the FDA agreed to commission an outside panel of experts to review their safety. ${ }^{120}$

\section{Drugs and Dietary Supplements: The Case of Pyridoxal 5-Phosphate}

Concerns about identification are not limited to conventional food and dietary supplements; there has also been confusion about the boundary between drugs and dietary supplements. For example, FDA's guidance on whether to submit an Investigational New Drug (IND) application raised concerns about its application to the dietary supplement industry. ${ }^{121}$ According to the draft IND guidance, an article is considered a drug when, among other things, it is being investigated for the "diagnosis, cure, mitigation, treatment, or prevention of disease." 122 However, although dietary supplement manufacturers may not make drug claims, according to DSHEA, a product can still be sold as a dietary supplement while it is being investigated for an IND if it was on the market as such prior to being approved as a new drug - unless the Secretary of HHS issues a regulation to the contrary. ${ }^{123}$

One example of a dietary supplement that falls into this grey area is pyridoxal 5-phosphate (P5P, a form of vitamin B6). In addition to currently being on the market as a dietary supplement, P5P is currently being investigated as an IND. The company that filed the IND has also filed a Citizen Petition $^{124}$ with the FDA, asserting that P5P is being marketed as an unapproved NDI, because

\footnotetext{
${ }^{117}$ For example, see Staff of Congressman Edward J. Markey, in coordination with the staff of Senators Richard J. Durbin and Richard Blumenthal, What's All the Buzz About?, A Survey of Popular Energy Drinks Finds Inconsistent Labeling, Questionable Ingredients, and Targeted Marketing to Adolescents, April 10, 2013, http://markey.house.gov/ sites/markey.house.gov/files/documents/2013-04-10_EnergyDrink_Report_0.pdf.

${ }^{118}$ Letter from Richard Durbin, Senator, and Richard Blumenthal, Senator, to Margaret Hamburg, Commissioner, U.S. Food and Drug Administration, September 11, 2012, http://durbin.senate.gov/public/index.cfm/files/serve?File_id= fe44b78e-32ae-41a0-8a61-2ddf14ab95d1.

119 Ibid.

${ }^{120}$ Food and Drug Administration, "Energy "Drinks" and Supplements: Investigation of Adverse Event Reports," press release, November 16, 2012, http://www.fda.gov/Food/NewsEvents/ucm328536.htm.

${ }^{121}$ Food and Drug Administration, Investigational New Drug Applications (INDs)_Determining Whether Human Research Studies Can Be Conducted Without an IND, Draft Guidance, Rockville, MD, October 2010, http://www.fda.gov/downloads/Drugs/Guidances/UCM229175.pdf.

${ }^{122}$ Ibid.

${ }^{123}$ P.L. 103-784, Section 3(a).

${ }^{124}$ FDA regulations permit any person to submit a Citizen Petition to FDA requesting the Commissioner to (1) issue, amend, or revoke a regulation or order; or (2) take or refrain from taking any other form of administrative action. 21 C.F.R. $\S 10.30$.
} 
there is no indication that it was on the market prior to DSHEA, and no one has filed NDI notification for P5P. ${ }^{125}$

Although the company that is investigating P5P as an IND has argued that P5P as a dietary supplement is technically an NDI and was never lawfully marketed prior to the petitioner's IND application, ${ }^{126}$ dietary supplement manufacturers disagree. They have argued that the Citizen Petition is a tactic to push P5P off the market as a dietary supplement, thereby diminishing competition for the petitioner. ${ }^{127}$ The dietary supplement industry is concerned that FDA action on this Citizen Petition could make it illegal to use P5P as a dietary supplement or dietary supplement ingredient, and that this would set a precedent for other dietary supplement ingredients that could be investigated as an IND. ${ }^{128}$ The Citizen Petition and associated public comments are currently under review by the FDA.

\section{The Role of Dietary Supplements in Health and Health Care}

Experts recommend that individuals meet their nutritional needs by eating a variety of foods, as outlined in the 2010 Dietary Guidelines for Americans. ${ }^{129}$ Some individuals take dietary supplements in order to meet those nutritional goals. Surveys show that over half of all Americans take dietary supplements, and that number has been increasing, ${ }^{130}$ yet there does not appear to be a wide body of research on dietary supplements' role in the health care system and potential effects on health care costs.

Consensus has not been reached on the effectiveness of most dietary supplements, but privately and publicly funded research is ongoing. ${ }^{131}$ Specific supplements, such as folic acid, have been shown to greatly reduce the incidence of neural tube defects in infants; as a result of scientific consensus, folic acid supplementation is now considered a vital component of prenatal care. ${ }^{132}$ Calcium supplementation is also often recommended by physicians for bone health, although some studies find the evidence of benefits is inconclusive. ${ }^{133}$ Yet there is a dearth of peerreviewed research on the effectiveness of many other supplements. As the FDA implements the NDI rule, one may be able to expect greater availability of research on newer additions to the dietary supplement market, due to the rule's requirements for substantiation.

\footnotetext{
${ }^{125}$ For contents of the petition see FDA-2007-P-0410-0002 : http://www.regulations.gov/\#!documentDetail;D=FDA2007-P-0410-0002.

126 Ibid.

${ }^{127}$ Alliance for Natural Health, "Vitamin B6 (P5P)," http://www.anh-usa.org/vitamin-b6-p5p/.

${ }^{128}$ The company that filed the IND also filed a Citizen Petition asserting that P5P is being marketed as an unapproved NDI, because there is no indication that it was on the market prior to DSHEA, and no one has filed NDI notification for P5P.

${ }^{129}$ U.S. Department of Agriculture, U.S. Department of Health and Human Services, Dietary Guidelines for Americans, 2010, Washington, DC, December 2010, http://health.gov.dietaryguidelines/2010.asp.

${ }^{130}$ Centers for Disease Control and Prevention, Dietary Supplement Use Among U.S. Adults Has Increased Since NHANES III (1988-1994), NCHS Data Brief, April 2011, http://www.ncbi.nlm.nih.gov/pubmed/21592424.

${ }^{131}$ The Office of Dietary Supplements at NIH, which funds dietary supplement research, was established under DHSEA. For more information, see http://ods.od.nih.gov/.

${ }^{132}$ For more information on folic acid, see http://www.cdc.gov/ncbddd/folicacid/index.html.

${ }^{133}$ For more information on calcium, see http://www.cdc.gov/nutrition/everyone/basics/vitamins/calcium.html. See also U.S. Preventive Services Task Force, Vitamin D and Calcium Supplementation to Prevent Fractures, Current Recommendations, February 2013, http://www.uspreventiveservicestaskforce.org/uspstf/uspsvitd.htm.
} 
Many physicians and their patients are reported to have a limited understanding of dietary supplement regulation, safety, and efficacy, which may be compounded by the limited availability of peer-reviewed medical research on the effects of dietary supplements. ${ }^{134}$ A 2010 report by the Government Accountability Office (GAO) found that consumers and medical professionals may be faced with a lack of objective information on the safety and efficacy of certain types of dietary supplements, dietary supplement ingredients, and potential side-effects or interactions with other medications. ${ }^{135}$ While prescription medications can be accounted for in their medical record, patients may or may not share information about their supplement intake with physicians. Additionally, some consumers may have limited understanding of the information provided on dietary supplement marketing materials. ${ }^{136}$ However, some physicians recommend dietary supplements to their patients based on the available literature, and still more patients take supplements based on their own research and concerns.

The federal government and the dietary supplement industry have taken steps to address consumer and health care provider understanding of dietary supplements through investment in research and the promotion of industry standards. ${ }^{137}$ The NIH and Department of Defense (DOD) have created websites and mobile applications to provide consumers with dietary supplement information. ${ }^{138}$ Some physicians' associations, such as the American Association of Endocrinologists, have published guidelines for the clinical use of dietary supplements, grading the quality and availability of evidence for each supplement reviewed. ${ }^{139}$ Industry groups have also initiated development of guidelines for use. ${ }^{140}$

Past Congresses have introduced legislation ${ }^{141}$ that would allow dietary supplement manufacturers to make claims that would be considered drug-like. ${ }^{142}$ Some research has shown that, if dietary supplements could be proven to be safe and effective in the prevention and/or treatment of specific health conditions through scientific research, and those benefits were accurately conveyed to consumers, use of those supplements could possibly yield cost savings for

\footnotetext{
${ }^{134}$ B Ashar, T Rice, and S Sisson, "Physicians' Understanding of the Regulation of Dietary Supplements," Arch Int Med, vol. 167, no. 9 (2007), pp. 966-969.

${ }^{135}$ U.S. Government Accountability Office, Herbal Dietary Supplements: Examples of Deceptive or Questionable Marketing Practices and Potentially Dangerous Advice, 10-662T, March 2010, http://www.gao.gov/assets/130/ 124769.pdf on Good Manufacturing Practices. For examples of proposed or adopted industry standards, see the American Herbal Products Association (www.ahpa.org); the Natural Products Association (www.npainfo.org); and the Council for Responsible Nutrition (www.crnusa.org).

${ }^{138}$ For example, see the Dietary Supplement Labels Database: http://dietarysupplements.nlm.nih.gov/dietary/; NIH's Office of Dietary Supplements: http://ods.od.nih.gov/; and DOD's Human Performance Readiness Center: http://hprconline.org/.

${ }^{139}$ AACE Nutrition Guidelines Task Force, American Association of Clinical Endocrinologists Medical Guidelines for the Clinical Use of Dietary Supplements and Nutraceuticals, September 2003, https://www.aace.com/files/ nutraceuticals-2003.pdf.

${ }^{140}$ For example, the Council for Responsible Nutrition publishes voluntary dosage recommendations and other guidance for dietary supplement manufacturers. See http://www.crnusa.org/pdfs/ CRN_Recommended_Voluntary_Dosage_Recs0309.pdf.

${ }^{141}$ H.R. 1364, $112^{\text {th }}$ Congress.

142 That is, to make claims that their products "diagnose, mitigate, treat, cure, or prevent a disease or specific class of diseases" as long as that claim is supported by "legitimate scientific research" as defined in H.R. 1364, $112^{\text {th }}$ Congress.
} 
consumers. ${ }^{143}$ Conversely, the cost of conducting and documenting the research required to prove health related claims to the FDA (such as randomized, controlled trials) in addition to proving safety for each product could affect the cost of the supplement to consumers. Industry has noted this in comments to the FDA. ${ }^{144}$ Currently, whether or not certain supplements are effective, they may still have an effect on the health care system if they keep a patient out of a doctor's office (although this could have either a positive or negative outcome, in terms of both cost and health). ${ }^{145}$

As the popularity of dietary supplements continues to grow, some patients and industry advocates are pushing for certain supplements to be treated as medical care for the purposes of health savings account eligibility. ${ }^{146}$ Advocates of this approach argue that supplements are being used to enhance the health and well-being of individuals, and in theory maintain consumers' health, and thus should be eligible for purchase with funds from health care savings accounts. Some employer-sponsored health care savings accounts currently allow dietary supplements as an eligible expense in certain circumstances. ${ }^{147}$

\section{Dietary Supplement Safety}

Regardless of the form or the reasons for which they are consumed, there is consensus that dietary supplements consumed by Americans should be safe and effective. However, there remains disagreement on how to achieve the goals of safety and efficacy. According to public opinion polls, the American public overwhelmingly assumes that FDA reviews the safety and effectiveness of dietary supplements before they are marketed. ${ }^{148}$ While this is the case for drugs and some medical devices, it is not the case for dietary supplements.

As noted earlier in this report, the FDA has the authority to regulate dietary supplements once they are on the market, and can inspect facilities to ensure compliance with GMP; ensure proper labeling and use of claims; and monitor adverse event reports. Additionally, the FTC monitors dietary supplement advertising for compliance with its guidelines. The dietary supplement industry has also taken steps toward self-regulation, by developing industry standards of quality and safety and creating third-party certification programs. ${ }^{149}$

\footnotetext{
${ }^{143}$ J DaVanzo et al., Cost Effectsof Five Dietary Supplements, The Lewin Group, Final Report, March 2005 , http://www.naturalproductsinfo.org/clientuploads/healthimpact1.pdf. The report studied (1) calcium (with vitamin D), (2) folic acid, (3) omega-3 fatty acids, (4) glucosamine, and (5) saw palmetto.

${ }^{144}$ Letter from Douglas MacKay, Vice President, Scientific and Regulatory Affairs, Council for Responsible Nutrition, to Division of Docket Management, Food and Drug Administration, July 25, 2011, http://www.crnusa.org/pdfs/ CRNComments FDAProposedCollectionInfo_SubstantiationDSClaimsUnderFDCAct072511.pdf.

145 J Umhau, K Garg, and A Woodward, "Dietary Supplements and Their Future in Health Care: Commentary on Draft Guidelines Proposed by the Food and Drug Administration," Antioxidants \& Redox Signaling, vol. 16, no. 5 (2012), pp. 461-462.

${ }^{146}$ For example, see S. 1098, $112^{\text {th }}$ Congress. For information on health savings accounts, see CRS Report RS21573, Tax-Advantaged Accounts for Health Care Expenses: Side-by-Side Comparison, by Carol Rapaport.

${ }^{147}$ For example, see the FSA Feds Health and Dependent Care Accounts Juke Box at https://www.fsafeds.com/fsafeds/ eligibleexpenses.asp.

148 "What's Behind our Dietary Supplements Coverage," Consumer Reports, January 2011, http://www.consumerreports.org/cro/2012/04/what-s-behind-our-dietary-supplements-coverage/index.htm.

${ }^{149}$ For example, NSF International offers testing and certification of dietary supplements for quality, contamination, and label claim verification. See http://www.nsf.org/business/dietary_supplements/index.asp?program=DietarySups. The U.S. Pharmacopeia also sets standards and verifies the quality, purity, and potency of ingredients and finished (continued...)
} 
FDA's interpretation of its authorities through the rulemaking process is a source of disagreement between FDA and the dietary supplement industry. ${ }^{150}$ For example, industry advocates have argued that FDA's draft NDI regulations undermine DSHEA because the FDA is now holding dietary supplements to the same safety standards as food additives, which was not Congress' intent. ${ }^{151}$ They have also expressed concerns about duplicative submissions, the level of safety data required, and the definition of grandfathered ingredients. ${ }^{152}$ Public health advocates argue that scientific evidence is necessary to demonstrate product safety, as these products continue to grow in popularity and usage. ${ }^{153}$ However, industry advocates believe the cost of proving NDI safety will be too burdensome, and will cause some manufacturers to drop production of certain supplements. ${ }^{154}$ Some Members of Congress concur, and have written the FDA urging the agency to rewrite the NDI guidance in a manner that would not increase barriers to market entry for new dietary supplement companies and products. ${ }^{155}$

Some argue that FDA's ability to identify safety concerns associated with dietary supplements is undermined by a lack of scientific information that is available for other regulated products, such as drugs. ${ }^{156}$ Industry representatives argue that most dietary supplement ingredients have a history of safe use in humans, and therefore should not be held to the same standard as drugs, and that newer additions to the supplement market will be required to go through the NDI notification process. For adulterated and some misbranded products, the FDA now has mandatory recall authority (as of FSMA), although the burden of proof remains on the FDA. In the past, the process for FDA to prove a significant or unreasonable risk was lengthy. For example, it took the FDA 10 years to amass enough data to meet the statutory burden of proof for banning Ephedra from the market. ${ }^{157}$

\footnotetext{
(...continued)

products. For more information on "USP Verified" products, see http://www.usp.org/usp-verification-services/uspverified-dietary-supplements.

${ }^{150}$ Natural Products Insider, "FDA Reportedly to Revisit NDI Draft Guidance,” press release, June 19, 2012, http://www.naturalproductsinsider.com/news/2012/06/fda-reportedly-to-revisit-ndi-draft-guidance.aspx.

${ }^{151}$ For example, see Hyman Phelps \& McNamara, P.C., "HP\&M Files Comments on Draft NDI Guidance; Request Withdrawal and Reissuance Reflecting DSHEA Intent," press release, December 7, 2011, http://www.fdalawblog.net/ fda_law_blog_hyman_phelps/2011/12/hpm-files-comments-to-draft-ndi-guidance-request-withdrawal-and-reissuancereflecting-dshea-intent.html.

${ }^{152}$ Letter from John Gay, Executive Director and CEO, Natural Products Association, and Cara Welch, Vice President, Scientific and Regulatory Affairs, to U.S. Food and Drug Administration, Division of Dockets Management, November 30, 2011, http://www.npainfo.org/App_Themes/NPA/docs/regulatoryLegislative/

NPAComments\%20NDI\%20Draft\%20Guidance\%20-\%20113011.pdf.

${ }^{153}$ B Denham, "Dietary Supplements_-Regulatory Issues and Implications for Public Health,” JAMA, vol. 306, no. 4 (July 27, 2011), pp. 428-429.

${ }^{154}$ Natural Products Association, "NDI Draft Guidance,” press release, http://www.npainfo.org/NPA/Advocacy/ NDIDraftGuidance.aspx.

${ }^{155}$ Letter from Members of the House Energy and Commerce Committee to Margaret Hamburg, Commissioner, U.S. Food and Drug Administration, March 29, 2012, http://www.anh-usa.org/wp-content/uploads/2012/04/NDI-

3.29.12.pdf.

${ }^{156}$ B Denham, "Dietary Supplements-Regulatory Issues and Implications for Public Health,” JAMA, vol. 306, no. 4 (July 27, 2011), pp. 428-429. See also Dietary Supplements: FDA May Have Opportunities to Expand itsUse of Reported Health Problems to Oversee Products, GAO-13-244, March 2013, p. 1, http://www.gao.gov/products/GAO13-244.

${ }^{157}$ U.S. Government Accountability Office, Food Safety: FDA Has Begun to Take Action to Address Weaknesses in Food Safety Research, but Gaps Remain, 10-182R, April 23, 2010, p. 10, http://www.gao.gov/assets/100/96676.pdf.
} 
Some have claimed that FDA's current enforcement policies overstep the agency's authority and violate the First Amendment, while others have deemed the agency's enforcement policies "anemic." 158 Past inspections by the FDA have found dietary supplements that contain undeclared or deceptively labeled ingredients. ${ }^{159}$ These products are often promoted for weight loss, sexual enhancement, and bodybuilding. FSMA provided FDA the authority to notify the Drug Enforcement Agency (DEA) when it determines that an NDI may contain an anabolic steroid or its analogue. ${ }^{160}$ In response to recent findings, the FDA wrote a letter to industry communicating its legal obligation and responsibility to prevent tainted products from reaching the U.S. market, highlighting a new rapid public notification system to warn consumers about those products and a mechanism for manufacturers to notify FDA about potentially tainted products. ${ }^{161}$ FDA has publicly warned consumers about these products and had provided consumer information bulletins on how to consider whether a supplement is safe or not. ${ }^{162}$

Despite new FDA post-market authorities and industry standard and certification programs, the public is still faced with examples of inconsistent potency and quality (including that of compounded dietary supplements, which are currently not subject to GMP) ${ }^{163}$, unsubstantiated claims made by manufacturers, and illegal or unapproved ingredients that render supplements adulterated. For example, the FDA recently issued a number of warning letters to manufacturers who may not be following the NDI guidelines. In April 2012, the agency issued warning letters to 10 dietary supplement manufacturers for marketing products containing dimethylamylamine (DMAA) without submitting an NDI notification. ${ }^{164}$ Plaintiffs have used these warning letters to bring lawsuits against those companies. ${ }^{165}$

FDA has taken steps in recent years to address oversight of dietary supplement safety. ${ }^{166}$ Enforcement of existing laws and regulations is generally restricted by funding, and the agency's discretionary budget authority has remained relatively flat in recent years. ${ }^{167}$ The agency also has

\footnotetext{
${ }^{158}$ Masoudi G and Pruitt C, "The Food and Drug Administration V. the First Amendment: A Survey of Recent FDA Enforcement," Health Matrix, vol. 21 (2011), pp. 111-147.

159 These may include, but are not limited to: active ingredients in FDA-approved drugs or their analogues; other compounds that do not qualify as dietary ingredients, such as novel synthetic steroids.

${ }^{160}$ P.L. 111-353, Section 113.

${ }^{161}$ Food and Drug Administration, "FDA: Tainted Products Marketed as Dietary Supplements Potentially Dangerous," press release, December 15, 2010, http://www.fda.gov/NewsEvents/Newsroom/PressAnnouncements/ucm236967.htm.

${ }^{162}$ Food and Drug Administration, Tainted Products Marketed as Dietary Supplements, Consumer Health Information, December 2010, http://www.fda.gov/consumer/consumernews.html.

${ }^{163}$ Drug compounding, or the process of combining, mixing, or altering ingredients, has recently been of interest to Congress. Some pharmacies also engage in compounding dietary supplements, although it has not been the focus of recent compounding concerns. For more information on drug compounding, see CRS Report R40503, FDA's Authority to Regulate Drug Compounding: A Legal Analysis, by Jennifer Staman, and CRS Report R43038, Federal Authority to Regulate the Compounding of Human Drugs, by Andrew Nolan.

${ }^{164}$ U.S. Food and Drug Administration, "FDA Challenges Marketing of DMAA Products for Lack of Safety Evidence," press release, April 27, 2012, http://www.fda.gov/NewsEvents/Newsroom/PressAnnouncements/ ucm302133.htm. In April 2013, the FDA issued a consumer update explaining the health risks to consumers and reiterating the warning to manufacturers: http://www.fda.gov/ForConsumers/ConsumerUpdates/ucm347270.htm.

${ }^{165}$ N Singer and P Lattman, "Is the Seller to Blame? Workout Supplement Challenged After Death of Soldier," The New York Times, March 15, 2013, online edition.

${ }^{166}$ For example, by increasing inspections: see Dietary Supplements: FDA May Have Opportunities to Expand its Use of Reported Health Problems to Oversee Products, GAO-13-244, March 2013, p. 1, http://www.gao.gov/products/ GAO-13-244.

${ }^{167}$ U.S. Food and Drug Administration, FY2014 Congressional Budget Justification, http://www.fda.gov/downloads/ (continued...)
} 
increased regulatory responsibilities under FSMA. ${ }^{168}$ Despite these potential constraints, the increased awareness of issues due to mandatory serious adverse event reporting has led the FDA to increase dietary supplement facility inspections and other enforcement actions since $2008 .{ }^{169}$

Industry groups and other advocates have historically challenged regulations that are perceived to overstep FDA's authority under the FFDCA. Legislative action often moves forward once industry, Congress, and the FDA achieve consensus. For example, adverse event reporting was strengthened once Congress, scientific advisory committees, industry, and consumers established consensus on the issue, ${ }^{170}$ and the mandatory recall authority proffered by FSMA was also supported by industry representatives. ${ }^{171}$

\section{Concluding Comments}

Consumers, the health care and dietary supplement industries, Congress, and federal regulators all have a stake in supplement identification, effectiveness, and safety. Research into the effectiveness and safety of supplements, industry compliance, surveillance and effective reporting strategies, and enforcement of current authorities are perennial concerns in this area.

With each legislative and regulatory action over the years, Congress and FDA have tried to balance often conflicting goals:

- safety and effectiveness;

- access to up-to-date, complete, and unbiased information on dietary supplements;

- accurate reporting of adverse events; and

- consumer choice.

Congress has demonstrated a sustained interest in dietary supplement related issues. It is uncertain if the $113^{\text {th }}$ Congress will pass any new dietary supplement related legislation. Such issues may arise in the broader context of congressional interest in nutrition and food safety.

(...continued)

AboutFDA/ReportsManualsForms/Reports/BudgetReports/UCM347422.pdf.

${ }^{168}$ P.L. 111-353.

${ }^{169}$ Dietary Supplements: FDA May Have Opportunities to Expand its Use of Reported Health Problems to Oversee Products, GAO-13-244, March 2013, p. 1, http://www.gao.gov/products/GAO-13-244.

${ }^{170}$ Michael McGuffin, President, American Herbal Products Association, "Mission and Functions of the American Herbal Products Association," Presentation, ODS Practicum, June 2011, http://www.ahpa.org/Portals/0/members/ 11_0608_McGuffin_ODS_Practicum_AHPA.pdf.

${ }^{171}$ NutraIngredients-USA, “'Industry is Addressing its Problems': NPA/CRN Set the Record Straight Over Arch Intern Med Commentary ," press release, August 20, 2012, http://www.nutraingredients-usa.com/Regulation/Industry-isaddressing-its-problems-NPA-CRN-set-the-record-straight-over-Arch-Intern-Med-commentary. 


\section{Appendix A. Selected Laws Regulating Dietary Supplements}

\section{Federal Food, Drug, and Cosmetic Act (P.L. 75-717)}

The FFDCA provides FDA with the authority to oversee the safety of food, drugs, and cosmetics.

\section{Nutrition Labeling and Education Act of 1990 (P.L. 101-535)}

The Nutrition Labeling and Education Act (NLEA) amended the FFDCA to require most foods, including dietary supplements, to bear nutrition labeling. It provided required information for labels and required the FDA to promulgate regulations regarding nutrition labeling and health claim requirements for foods and dietary supplements.

\section{Prescription Drug User Fee Act of 1992 (P.L. 102-571)}

Title II of the Prescription Drug User Fee Act is referred to as the "Dietary Supplement Act of 1992 " and required a one-year moratorium on FDA's implementation of dietary supplement labeling under NLEA.

\section{Dietary Supplement Health and Education Act of 1994 (P.L. 103-417)}

The Dietary Supplement Health and Education Act (DSHEA) amended the FFDCA to create new manufacturing and labeling requirements for dietary supplements, and established the Office of Dietary Supplements within the National Institutes of Health.

\section{Public Health Security and Bioterrorism Preparedness and Response Act of 2002 (P.L. 107-188)}

This law mandates a chain of possession identification (manufacturer, processor, packer, distributor, and other possessors) for those firms that seek to import components of drugs, devices, food additives, color additives, or dietary supplements for further processing and export.

\section{Dietary Supplement and Nonprescription Drug Consumer Protection Act (P.L. 109-462)}

This law mandates the reporting of any dietary supplement related serious adverse event to the FDA within 15 days of the event. Serious adverse event reporting is mandatory for manufacturers, packers, or distributors whose name appears on the dietary supplement label. 


\section{FDA Food Safety Modernization Act (P.L. 111-353)}

FSMA provides FDA with mandatory recall authority for food, including dietary supplements. This law also requires FDA to issue NDI guidance no later than 180 after its enactment. 


\section{Appendix B. Principal Display Panel, Dietary Supplements}

Figure B-I. Example of a Dietary Supplement Principal Display Panel

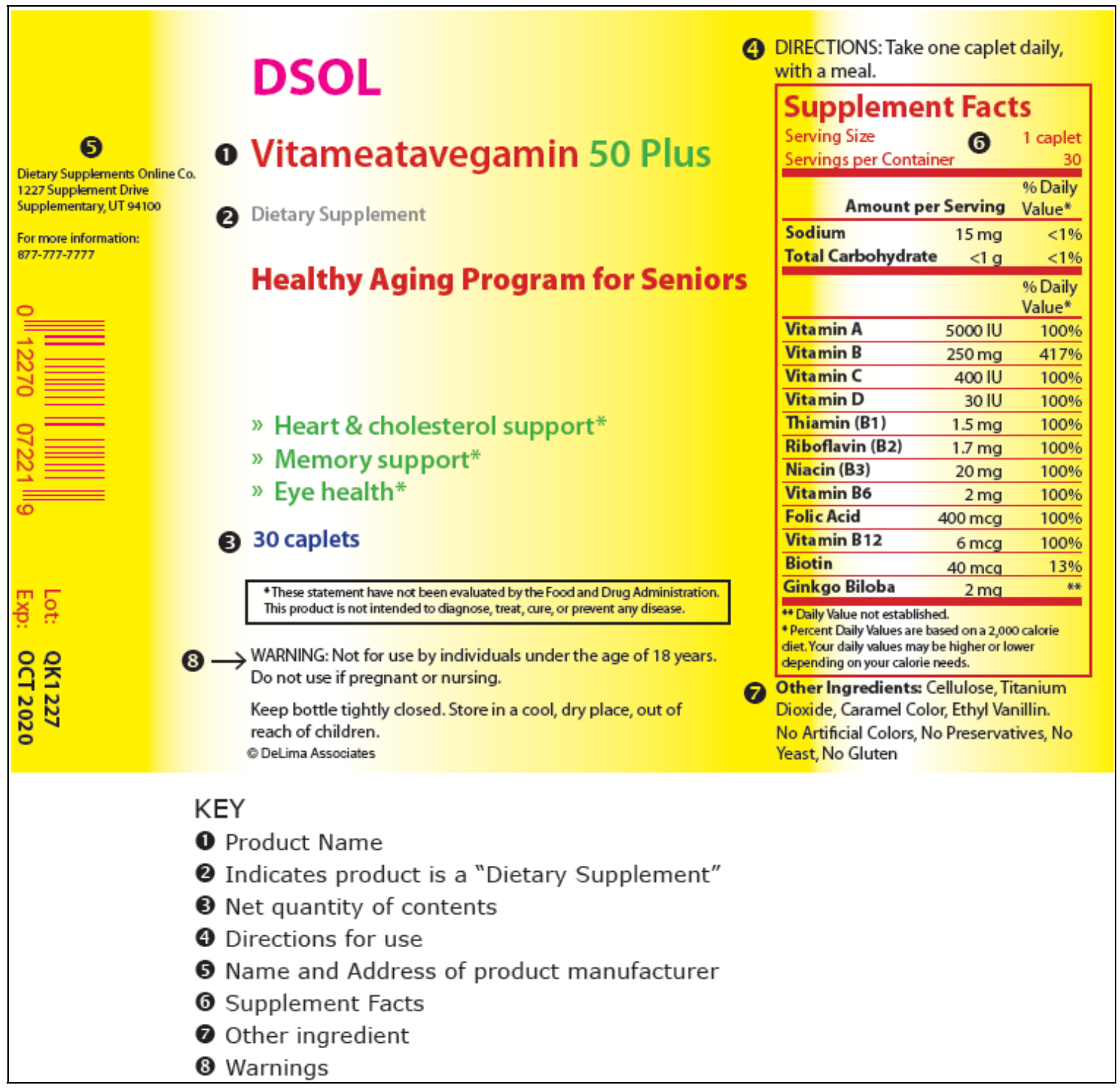

Source: National Institutes of Health, Dietary Supplements Labels Database at the National Library of Medicine, http://dietarysupplements.nlm.nih.gov/dietary/faq I6.pdf. 


\section{Appendix C. Acronyms Used in This Report}

\section{Government Agencies}

- CDC-Centers for Disease Control and Prevention

- CFSAN - Center for Food Safety and Applied Nutrition, Office of Foods, FDA

- FDA-U.S. Food and Drug Administration

- $\quad$ FTC-Federal Trade Commission

- GAO-U.S. Government Accountability Office

- OIG-Office of the Inspector General, U.S. Department of Health and Human Services

\section{Legislation}

- DSHEA - Dietary Supplement Health and Education Act of 1994

- FDAMA-FDA Modernization Act

- FFDCA - Federal Food, Drug, and Cosmetics Act

- FSMA-FDA Food Safety Modernization Act of 2011

- NLEA-Nutrition Labeling and Education Act of 1990

\section{Miscellaneous}

- CFR-Code of Federal Regulations

- FAERS-FDA Adverse Event Reporting System

- GMP - Good Manufacturing Practices

- GRAS - Generally Recognized as Safe

- $\quad$ NDI-New Dietary Ingredient

- SSA-FDA's Significant Scientific Agreement Standard for approved health claims

- IND - Investigational New Drug 


\section{Author Contact Information}

Amalia K. Corby-Edwards

Analyst in Public Health and Epidemiology

acorbyedwards@crs.loc.gov, 7-0423

\section{Acknowledgments}

Jaime Hastings, visiting intern, and Ada Cornell, Information Research Specialist, contributed to this report. 